\title{
The Clash of Scientific Assessors: What the Conflict over Glyphosate Carcinogenicity Tells Us about the Relationship between Law and Science
}

\author{
Vesco PASKALEV* (1D
}

The recent reauthorisation of glyphosate in the European Union is a uniquely suitable opportunity to study the relationships between law and science because, unlike many other controversies that are commonly perceived through the scienceldemocracy dichotomy, in this case the disagreement was between the "scientific" assessments of two purely "expert" bodies, the International Agency for Research on Cancer (IARC) and the European Food Safety Authority (EFSA). This paper takes a close look at some details of the two assessments to show how scientific assessments are shaped by the legal environment to such an extent that it is impossible to separate "legal" from "technical" issues at any level; they are entangled together "all the way down". Furthermore, it identifies three side effects of this entanglement that were previously unnoticed. First, obscure legal rules may provide (usually unintended) leverage to some of the parties. In turn, this forces everybody into proxy wars on the issue where the leverage is, at the expense of all other concerns that they may legitimately have. Finally, despite the strict legal regimentation of the scientific assessment, significant space for judgment remains, and discretion is never removed, only shifted to different places or levels.

\section{INTRODUCTION}

The controversy around the carcinogenicity of glyphosate has barely subsided since 2017 when the European Commission reauthorised the herbicide for another five years, and the main contestants are already embroiled in the next battle. ${ }^{1}$ This case has generated a significant amount of academic literature already, so the basic facts are relatively well known and do not need further elaboration. While most of the ink was spilled on the question of whether glyphosate is "probably carcinogenic", ${ }^{2}$ this article will study

\footnotetext{
* Brunel University London, Brunel Law School, Elliot Jacques Building, Room 115, Kingston Ln, Uxbridge, UB8 3PH, UK; email: vesco.paskalev@ brunel.ac.uk.

1 It started officially on 12 December 2019 when the Glyphosate Renewal Group filed its application for authorisation in the post-2022 period.

2 If interested, a summary of the evidence that is readable for non-scientists is available in M Kogevinas, "Probable carcinogenicity of glyphosate" (2019) 365 British Medical Journal 11613.
} 
how each of the main players - the International Agency for Research on Cancer (IARC) and the European Food Safety Authority (EFSA) - arrived at their respective conclusions, which in the view of the author is telling for the more general question about the relationship between "law" and "science". The most apparent way in which law shaped the scientific advice is by determining the scope of the safety assessment and, as we shall see, by making carcinogenicity rather than, say, endocrine disruption pivotal for the conclusion. In this way, an obscure piece of legislation - the Plant Protection Products Regulation ${ }^{3}$ - shaped both the discourse in the public sphere and the scientific advice. Thus, by studying how IARC and EFSA produced their respective pieces of scientific advice on the safety of glyphosate, the article will show how law is entangled with science, determining the scope of scientific assessments and even the weighting of different types of evidence, what are the implications of this entanglement for the parties involved and their power and, in turn, how "technical" details in the decisional framework can have important legal and political consequences. In the following section (Section II), I shall make several preliminary observations to clear the way for the main argument developed in the remainder of the article. In Sections III and IV, I shall look into some details of the decision-making in IARC and EFSA, respectively. This will hopefully make clear the depth of the entanglement between the legal and the scientific, which will be further analysed in Section V. Then, I shall identify three neglected side effects of the science-based risk assessment process, which I shall call proxy wars, leverage (Section VI) and choice (Section VII).

\section{Preliminary observations}

With my inquiry so defined, in this section I shall briefly touch upon several issues that came to the fore in this controversy that are not directly related to the subject yet featured too prominently to go unmentioned. First, the glyphosate saga was not a conflict between "science" and "democracy". ${ }^{4}$ Unlike other similar controversies (eg genetically modified organisms (GMOs), hormone-treated beef, "chlorinated chicken", etc.), in this case the two camps were organised around two "scientific" agencies. Both IARC and EFSA are expert, independent and presumably insulated from political influences, yet they came to uncharacteristically bitter disagreement with each other. Second, in my view, this disagreement, unseemly as it was, is not a problem. Elsewhere I have argued that, contrary to the widespread assumption of the universality of science, questions of safety are very much context-dependent, and therefore it is legitimate for different assessors to reach different conclusions on what appears to be the same question. ${ }^{5}$ Academics often note that good decision-making does not mean uncontested decision-making, ${ }^{6}$ yet this is against the common understanding of the role of

3 Regulation 1107/2009 concerning the placing of plant protection products on the market.

4 The science/democracy dichotomy is a misguided but nevertheless persistent popular explanation of such conflicts. For comprehensive criticism, see E Fisher, Risk Regulation and Administrative Constitutionalism (Oxford, Hart Publishing 2007).

5 V Paskalev, "May Science Be with You: Can Scientific Expertise Confer Legitimacy to Transnational Authority?" (2017) 8 Transnational Legal Theory 202.

6 See eg Fisher, supra, note 4, pp 252-53. 
"Science". Characteristically, Bernard Url, the head of EFSA, recently stated, "Good science is the same all over the world. It does not matter where it is produced". ${ }^{7}$ Indeed, in the established paradigm of "science-based" regulation, Science is usually expected to give the (one) right answer. As this case demonstrated, this assumption cannot always hold true, so perhaps it is time for us to abandon it altogether and rethink the science-based framework that is built on it. This argument, however, is for another day.

The other set of problems raised by this controversy are the alleged bias of the agencies and the undue influence of the industry on the regulatory process. ${ }^{8}$ For the present purposes it is helpful to distinguish between the two, as only the former is directly relevant. The bias may be an unavoidable feature of the law. Indeed, the Science and Technology Scholarship (STS) and the Critical Legal Studies before them have amply demonstrated how apparently neutral rules systematically work to the advantage of certain interests, and below I shall show how particular provisions of the Plant Protection Products Regulation privilege certain types of evidence at the expense of others. On the other hand, in certain cases, certain stakeholders may be able to exert more influence on the decision-making process, not because of the imperfection of the rules, but despite the conscious effort of the legislator to prevent such influences. In this case, the glyphosate authorisation was allegedly vitiated by the undue influence of its leading producer, Monsanto (now part of Bayer). First, it appeared that large parts of the Renewal Assessment Report (RAR), prepared by the German Federal Institute for Risk Assessment (BfR) on which EFSA eventually based its conclusions, were copy-pasted from Monsanto's application form. ${ }^{9}$ Second, in the aftermath of IARCs classification, Monsanto spent some 17 million USD on manufacturing uncertainty, such as by paying "independent" scientists to publish peer-reviewed articles critical of IARC. ${ }^{10}$ Yet, the analysis below should make clear that the conclusions reached by each agency were shaped by the applicable regulations in place, and in my view these structural reasons cannot be changed by BfR cutting corners. ${ }^{11}$ This is not to say that undue influence is not invidious

7 "EFSA boss: Our advice should not be misused for short-term political interests", Euractiv, 17 September 2018 $<$ https://www.euractiv.com/section/agriculture-food/interview/efsa-boss-our-advice-should-not-be-misused-for-shortterm-political-interests $>$ (last accessed 11 November 2019).

8 This distinction is inspired by, but not identical to, Arcuri's concept of disinterested interest and her distinction between interests that are legitimate (eg awareness of the social consequences of scientific conclusions) and vested interests (eg of regulates). See A Arcuri, "Three Dimensions of Accountability for Global Technocracy" in A Arcuri and F Coman-Kund (eds), Technocracy and the Law: Accountability, Governance and Expertise (Abingdon, Routledge 2020).

9 BfR, Renewal Assessment Report (RAR) on the active substance glyphosate prepared by the rapporteur Member State Germany in the framework of Regulation (EU) No 1141/2010, December 2013. In response to the allegations, EFSA stated, "If the [assessor] agrees with a particular summary or evaluation it may incorporate the text directly into the draft assessment report", see its press release from 22 September $2017<\mathrm{https}$ ://www.efsa.europa.eu/sites/ default/files/170922_glyphosate_statement.pdf $>$ (last accessed on 8 April 2020).

10 See "Monsanto Exec Reveals \$17 Million Budget For Anti-IARC, Pro-Glyphosate Efforts" US Right to Know $<$ https://usrtk.org/monsanto-roundup-trial-tacker/monsanto-executive-reveals-17-million-for-anti-iarc-pro-glyphosateefforts $>$ (last accessed 11 November 2019). For an academic analysis of the declassified industry documents, see L McHenry, "Monsanto papers: Poisoning the scientific well" (2018) 29(3-4) International Journal of Risk and Safety in Medicine 193.

11 In that regard, it is worth noting that the committee established by the European Parliament to investigate the integrity of the pesticide authorisation process dedicated just one paragraph (no. 51) to plagiarism (perhaps the only unequivocally critical paragraph in its whole report) while making dozens of recommendations directed at a change of the evidential basis, weighting of evidence, transparency, etc. See European Parliament resolution of 16 January 2019 on the Union's authorisation procedure for pesticides (2018/2153(INI)). 
and harmful in other ways and should not be counteracted, but if the analysis below is correct, the reasons for agencies' conclusions are systemic rather than contingent on the pressures on their staff.

Thus, in the view of the author, both agencies were acting as they are required to by the respective rulebooks and terms of reference, with reasonable levels of integrity, transparency and accountability. It is ironic that the accounts they were giving actually fuelled the controversy, as both agencies provided ample epistemic resources to each other's critics. Indeed, if the agencies were less open, their conclusions would be much less vulnerable to contestations by the parties unhappy with the outcome. ${ }^{12}$ This is not to say that such decisions should be "black-boxed" - although black-boxing in some cases may be necessary. ${ }^{13}$ While it is sometimes lamented that transparency allows for "politicisation" of the expert assessments, I believe the "politicisation" of the issue in this case would be quite appropriate given the widespread use of the glyphosate and the far-reaching implications of its (non-)authorisation.

Thirdly, in my view, the biggest problem in this authorisation - and of the risk regulation regime of the European Union (EU) - was the narrow framing of the issue, which made the possible carcinogenicity pivotal for the decision and thus led to two of the undesired effects discussed below - undue leverage and proxy war - while obscuring many other factors that may have been even more important for some stakeholders. Indeed, one would expect that as the most popular herbicide in the world, glyphosate would raise quite a few issues in the course of its reauthorisation. Although various environmental non-governmental organisations (NGOs) had been voicing concerns long before 2015, carcinogenicity was not central even for them. For example, a report by Friends of the Earth (FoE) from 2013 mentioned carcinogenicity only once, along with a number of other serious issues: endocrine disruption, loss of farmland biodiversity, water contamination, soil health, etc. ${ }^{14}$ At that point in time, FoE was highly concerned about glyphosate, but its demands did not include an outright ban on glyphosate's use. There are other reasons for the environmentalists to dislike glyphosate not explicitly mentioned in the FoE report. The first that comes to mind is the complementarity between glyphosate and GMOs. The increasing dependence of farmers and food chains on a single corporation, Monsanto, is another. Furthermore, glyphosate allows simplified weed management, which favours the development of large-scale industrial farming; many objections are raised against this monocultures ("green deserts") are detrimental to biodiversity, displace small-scale farmers and whole communities, etc. There is also the concern that heavy use of pesticides breeds resistance, so a "safe" herbicide-resistant crop locks farmers, the biotech industry and regulators in a cycle of competition between evolution and innovation. The self-sustaining growth of demand for pesticides is much welcomed

\footnotetext{
12 Cf Fisher, who also notes that transparency creates more possibilities for contestation, even though it may have been introduced with the aim to build confidence; see E Fisher, "Transparency and Administrative Law: A Critical Evaluation" (2010) 63 Current Legal Problems 272.

13 See the discussion in S Jasanoff, "Transparency in Public Science: Purposes, Reasons, Limits" (2006) 69 Law and Contemporary Problems 21.

14 Friends of the Earth Europe, "Glyphosate - Media Briefing. Reasons for concern", 2013 <http://www.foeeurope. org/glyphosate-reasons-for-concern-briefing-130613 > (last accessed 27 March 2018). See also the accompanying, more detailed documents available there.
} 
by the industry, but progressively increases the effects on the environment well beyond the initial estimates. Next, the risk for particularly vulnerable groups, such as the residents in the vicinity of the sprayed fields, seems to be completely beyond the radar of both researchers and regulators. ${ }^{15}$ Last but not least, many people would consider the presence of glyphosate in our bodies as an issue of its own: even if it were completely harmless, we may not want it trusted into our bodies without anyone's consent. ${ }^{16}$

Readers should be forgiven if they have not heard any of these concerns voiced in the glyphosate reauthorisation debate. This is so because carcinogenicity took up almost all of the space in the public sphere. One does not need to agree with any of the concerns above to accept that they are legitimate factors to be considered before the decision to authorise glyphosate for the next 15 years throughout the continent is taken. Yet, under the existing "science-based" risk regulation paradigm, such considerations are all but excluded from the decision-making process. ${ }^{17}$ The focus on carcinogenicity took the attention away even from the precious little that could have been taken into account. It is important to emphasise that glyphosate protestors themselves focused on carcinogenicity alone, disregarding any other concerns they may have, because the availability of harmful effects on humans, animals and the environment is the only thing that really matters, ${ }^{18}$ and, as we shall see, carcinogenicity alone could warrant an outright ban. This framing of risk analysis has been subject to various criticisms as soon as the current paradigm for risk analysis took shape, ${ }^{19}$ yet it is adhered to throughout the world with remarkable persistence. It has also been noted that this framing, and in particular the arbitrary but nonetheless rigid division between risk assessment and risk management, shifts decision-making power upstream (ie to the earlier stages of the risk analysis), to less accountable and more obscure bodies. What is less well understood is that this system hides discretion, gives unaccounted and arbitrary advantages to some stakeholders and forces everybody into proxy wars. That is, instead of a robust public debate (or contestation) on all of the issues that the various stakeholders are concerned about, they are all forced to cling to a much narrower subset of issues that pass as "scientific". The glyphosate saga highlighted these three effects - choice, leverage and

15 See G Downs, "It's not just glyphosate and neonicotinoids! Why we need a pesticide-free future", The Ecologist, 30 April 2015.

16 Cf D Chalmers, "Risk, Anxiety and the European Mediation of the Politics of Life" (2005) 30 European Law Review 649.

17 As a matter of law, the "other factors" must be taken into account, yet they rarely are - a recent evaluation of the GFL states that "EU risk managers have considered other legitimate factors in addition to the scientific opinions of EFSA in deciding the appropriate measures to be taken in very few cases". See "Executive summary of the REFIT evaluation of the General Food Law", $\{\operatorname{SWD}(2018) 38$ final $\}$, emphasis in the original. It is unclear whether the European Commission considers this to be a problem or a virtue of the regime. I focus on this issue in a companion piece currently under review in another publication. For a more general discussion, see M Lee, "Beyond Safety? The Broadening Scope of Risk Regulation” (2009) 62 Current Legal Problems 242.

18 See the approval criteria in Art 4(3) of the Plant Protection Products Regulation. Further to the effect on humans, animals and the environment, the plant protection product must be effective (Art 4(3)(a)) and shall not cause unnecessary suffering of the target species (Art 4(3)(d)).

19 See S Jasanoff, "Relating Risk Assessment and Risk Management" (1993) 19 EPA Journal 37, for one of the early criticisms; for a comprehensive analysis and an alternative paradigm, see Fisher, supra, note 4. For yet other proposed alternatives, see O Renn and KD Walker (eds), Global Risk Governance: Concept and Practice Using the IRGC Framework (Berlin, Springer 2008); M Dreyer and O Renn, "EFSA's Involvement Policy: Moving towards an Analytic-Deliberative Process in EU Food Safety Governance ?" in C Holst (ed.), Expertise and Democracy (Oslo, ARENA Reports 2014) pp 323-52. 
proxy wars - and in the remainder of this article, I shall take a close look at the respective decisions of IARC and EFSA to demonstrate these effects.

The final preliminary issue to be noted is that this article is meant to be analytical rather than normative. I aim to show the interplay between law and science and will refrain from making any recommendations (except for where I consider possible alternatives only to make a point clearer). I believe that what the case study below demonstrates can be generalised to other instances of regulatory science. On the other hand, as a study of law in action, it is not for the present paper to discuss the reforms of the General Food Law (GFL) and related legislation introduced in $2019^{20}$ in response to the problems highlighted by the glyphosate authorisation. This would take another case study, possibly of the next glyphosate reauthorisation battle that is now underway.

\section{The International Agency for Research on Cancer}

IARC is an independent organisation within the framework of the World Health Organisation (WHO) based in Lyon, France. It sets up Working Groups of experts vetted for conflicts of interest who review the available scientific literature and convene for a week-long workshop where they aim to reach conclusions by consensus as to the possible carcinogenic effect of the assessed substance. ${ }^{21}$ IARC's detractors are keen to point out that it has classified as possible carcinogens red meat, night shifts and hairdressing, and that during its entire history it classified as safe (ie "probably not carcinogenic") only one substance. The latter is rhetorically effective, but it may not show the bias it is meant to, but rather that the substances that were prioritised for assessment were selected wisely. Most importantly, IARC is not a regulator and its decisions are not binding on anyone. Yet as Arcuri notes, it exercises a form of "liquid authority", and its opinions have significant effects in the legal realm. ${ }^{22}$

In 2014, a panel within IARC identified glyphosate as a substance of interest and assigned the review to a working group of 17 scientists; the concluding meeting of the latter was held on 3-10 March 2015 and the consensus conclusions were publicly announced on 20 March. ${ }^{23}$ The verdict was that there is "limited evidence" for

20 See the European Parliament legislative resolution of 17 April 2019 on the proposal for a Regulation of the European Parliament and of the Council on the transparency and sustainability of the EU risk assessment in the food chain amending Regulation (EC) No 178/2002 [on general food law], Directive 2001/18/EC [on the deliberate release into the environment of GMOs], Regulation (EC) No 1829/2003 [on GM food and feed], Regulation (EC) No 1831/2003 [on feed additives], Regulation (EC) No 2065/2003 [on smoke flavourings], Regulation (EC) No $1935 / 2004$ [on food contact materials], Regulation (EC) No 1331/2008 [on the common authorisation procedure for food additives, food enzymes and food flavourings], Regulation (EC) No 1107/2009 [on plant protection products] and Regulation (EU) No 2015/2283 [on novel foods] [2019] 2018/0088(COD).

21 There are five categories: carcinogenic to humans; probably carcinogenic; possibly carcinogenic; not classifiable as carcinogenic; and probably not carcinogenic. Details of the procedure are available on the IARC website, see $<$ monographs.iarc.fr/ENG/Preamble/currenta6work0706.php $>$.

22 A Arcuri, "Glyphosate" in J Homan and D Joyce (eds), International Law's Objects (Oxford, Oxford University Press 2019) pp 234-46.

23 For a summary see KZ Guyton, D Loomis, Y Grosse, F El Ghissassi, C Scoccianti, H Mattock, K Straif, on behalf of IARC WG, "Carcinogenicity of tetrachlorvinphos, parathion, malathion, diazinon, and glyphosate" (2015) 16(5) The Lancet Oncology 490. For the full Monograph, see IARC/WHO, "IARC Monographs: Some Organophosphate Insecticides and Herbicides" Volume 112, 2017 <http://monographs.iarc.fr/ENG/Monographs/vol112/index.php> (last accessed 7 November 2019). 
carcinogenicity in humans, "sufficient evidence" for carcinogenicity in animals and "strong evidence" for genotoxicity. This warranted classification of glyphosate as "probably carcinogenic for humans".

Several specific features of IARC should be noted. It takes into consideration only studies that are published after peer review. ${ }^{24}$ In this it is quite different from the regulators, which rely also, and often predominantly, on studies conducted or commissioned by the industry. Such studies are generally not available to IARC. ${ }^{25}$ Second, IARC's job is hazard identification, which is only the first part of the standard risk assessment. ${ }^{26}$ That is, it establishes the possibility for the substance to cause cancer, and the differences in its classification reflect only how certain the evidence for causal effect is, not the probability of the harm occurring. For the latter, account must also be taken of the dose response and the exposure, and this is done in risk assessment, which is usually conducted by regulatory bodies such as EFSA. ${ }^{27}$ The next key feature of IARC assessments is that it assesses both the active substances and the commercially available compounds, while EFSA considers only the former. As will be seen below, this difference in the subject matter entails differences in the epistemic base (ie the studies that can be taken into account). Certainly, these differences are based on the operational context of IARC and EFSA and, of course, have their legal basis in their foundational legal documents. Their importance cannot be overestimated because it is well known that this whole controversy pivoted on which studies could be taken into account and which could not. It is worth noting that these differences do not reflect apparent political choices: IARC's selection of studies does not reflect directly any values or bigger issues that may or may not be shared by its members. It merely reflects its foundational documents. Yet even though these rules are meant to ensure the independence and "objectivity" of the assessments, they are by no means neutral to the content thereof. Finally, it bears repetition that IARC's decisions do not bind anyone and do not have any direct policy consequences. IARC is in the rather unique position of not facing any trade-offs and it does not need to balance economic, social and health concerns.

Notwithstanding this, IARC's conclusions on glyphosate were far from indisputable. It is hardly surprising that they were challenged by the industry, but they were also disputed by scientific regulators all over the world, and the exchange with EFSA was particularly bitter. One could naively expect that in the Republic of Science ${ }^{28}$ expert advisors would be ready to accept each other's findings and to disagree only when an error is found. Any such disagreement would be temporary, lasting only until it is publicly exposed and the error corrected. Moreover, these expert advisors may have different epistemic policies (eg err on the safe side, delay decision until more data become available, etc.) depending on the known consequences of their decisions.

\footnotetext{
24 The entire assessment process at IARC is governed by the Preamble to its Monograph programmes, see IARC Monographs on the Evaluation of Carcinogenic Risks to Humans, Preamble 2006, p 4.

25 Note, however, that it may take such studies into account if their main findings become publicly available, such as when submitted to another regulator (eg the US Environmental Protection Agency (EPA), as will be seen below).

26 The other three being dose-response characterisation, exposure assessment and risk characterisation.

27 Strictly speaking, EFSA is not a regulator, as its opinions are only advisory - see below.

28 M Polanyi, "The Republic of Science: Its Political and Economic Theory" (1962) 1 Minerva 54.
} 
While IARC takes pride in its transparency, integrity and independence, when the stakes are high, no authority is contestation proof. It came under fire as soon as it came into the limelight with its glyphosate classification, ${ }^{29}$ and it faced allegations of conflicts of interest. The allegation that is relevant for the present article concerned the exclusion of a major study. The Agricultural Health Study (AHS) is a decadelong prospective research study conducted in the USA with nearly 90,000 farmers. An early publication (2005) based on this study found that "glyphosate exposure was not associated with cancer incidence overall". ${ }^{30}$ Since then, significant amounts of further data were gathered, adding more power to this finding. Allegedly, by 2013, this finding was clear to the researchers conducting the study, but it was not published until 2018. Crucially, one of the researchers, Dr Aaron Blair, was the chair of the IARC Working Group on glyphosate. Yet the new findings were not taken into account by the Working Group as the study was not yet published then, which is a key condition under IARC rules. Dr Blair did not even orally report the findings to his colleagues. While publishing results does take years, and such a huge research project yields many different results competing for researchers' attention, an investigation by Kate Kelland hints that it might be the case that Dr Blair was in a position to set the priorities and may have delayed this one to prevent its inclusion in the IARC review. ${ }^{31}$ On the other hand, this particular publication might have not made any difference, as IARC and EFSA were in agreement that the AHS research revealed no significant association between glyphosate and cancer. ${ }^{32}$ What is interesting for the present research is that if there had been foul play in this case at all, it would have been made possible by a rule meant to increase the transparency of IARC. On the other hand, the trickery could become visible only because this rule was in place such gaming of the system in other agencies could go on unnoticed. IARC issued several statements describing all of the allegations as misleading or false. ${ }^{33}$ On the issue regarding Dr Blair, IARC points to evidence that his views remained unaffected by the subsequent publication of the study. While the reader may interpret this (and all other controversial details) in light of their own beliefs and find faults and biases with each

\footnotetext{
29 See supra, note 10.

30 AJ De Roos et al, "Cancer incidence among glyphosate-exposed pesticide applicators in the Agricultural Health Study" (2005) 113(1) Environmental Health Perspectives 49.

31 K Kelland, "Cancer agency left in the dark over glyphosate evidence", Reuters, 14 June $2017<$ https://www. reuters.com/investigates/special-report/glyphosate-cancer-data> (last accessed 11 November 2019). Note, however, that Kelland herself was accused of spinning the evidence that was not obtained from court depositions as she claimed, but provided by Monsanto. See C Gillam, "New Monsanto Documents Expose Cozy Relationship to Reuters Reporter", US Right To Know, 25 April $2019<$ https://usrtk.org/monsanto-roundup-trial-tacker/newmonsanto-documents-expose-cozy-connection-to-reuters-reporter> (last accessed 11 November 2019).

32 E Bozzini, "Contrasting norms on the use of evidence in risk assessment: the controversy surrounding the carcinogenicity of glyphosate" (2020) Health Risk and Society (forthcoming). Note also that the AHS research is far from being undisputed evidence for the safety of glyphosate. As Portier and colleagues note, "the median follow-up time in the AHS was 6.7 years, which is unlikely to be long enough to account for cancer latency", see Portier et al, infra, note 72, p 743. It is also based on data from the USA, and there are no data for low- or middleincome countries where glyphosate's use is highest; see Kogevinas, supra, note 2.

33 See eg "IARC response to criticisms of the Monographs and the glyphosate evaluation" from January 2018 $<$ https://www.iarc.fr/wp-content/uploads/2018/07/IARC_response_to_criticisms_of_the_Monographs_and_the_ glyphosate_evaluation.pdf $>$ (last accessed 4 April 2020).
} 
side, what is important for the purposes of the present study is that IARC and its Working Group were strictly adhering to their respective rules.

Further to this, IARC's critics claim that its approach is lacking scientific rigour because its Working Groups include scientists who are reviewing their own research. ${ }^{34}$ For our purposes, it is important to note how integrity rules subtly shape the epistemic base of the final conclusions. It is almost by definition that the experts on an issue have conducted key studies of this issue themselves. Removing them, or their studies, will either deprive the decision-making body of key experts or key pieces of research. In any event, the head of IARC's monograph programme Kurt Straif claims that this is controlled for by IARC's rules. They provide that, first, the authors cannot directly evaluate their own studies and, second, the involvement of 20-30 people in the discussions neutralises individual interests. ${ }^{35}$ IARC stands behind its classification, but remains isolated: regulators around the world conducted own assessments and reached opposite conclusions. In the same year, the US Environment Protection Agency (EPA) decided that glyphosate is not carcinogenic, and so did BfR conducting preparatory work for EFSA.

\section{European Food Safety Authority}

EFSA is one of the stronger agencies in the EU, having been set up to advise the Commission on a wide variety of issues, some of which may be only indirectly related to food and feed (eg bisphenol A). Its job is to conduct risk assessments as advice to the Commission and/or the Member States (ie the national experts in the comitology committees) who are the risk managers. Although its opinions are not binding, the Commission tends to follow them, and it often claims that it is obliged to do so. ${ }^{36}$

Its independence is contested. Perhaps it is the most institutionally independent of all EU agencies, as the 14 members of its Management Board are not representatives of the Member States (which is the case for most newer agencies). ${ }^{37}$ There is one Commission representative and four representatives of consumer or other stakeholder organisations, and the remaining nine are independent experts. But its independence from the market players has generated quite a lot controversies and at least one major scandal. On the one

\footnotetext{
34 RE Tarone, "On the International Agency for Research on Cancer Classification of Glyphosate as a Probable Human Carcinogen" (2018) 27 European Journal of Cancer Prevention 82. See also K Kelland, "How the World Health Organization's cancer agency confuses consumers", Reuters, 18 April $2016<$ https://www.reuters.com/ investigates/special-report/health-who-iarc> (last accessed 4 April 2020).

35 Kelland, supra, note 31.

36 The GFL obliges the Commission to consider but not to follow EFSA's advice. However, in Pfizer (T-99/2000), the General Court held that in order to deviate from the received advice, Union institutions must justify their choice with scientific evidence of the same quality, which in most cases will be a tall order. Indeed, on a number of occasions, Commission officials have made public statements that they are obliged to follow such "advice". For further discussion, see V Paskalev, "GMO Regulation in Europe: Undue Delegation, Abdication or Design Flaw?" (2015) 5(4) European Journal of Risk Regulation 573.

37 Many studies found that EU agencies, EFSA included, are subject to much tighter control by the Commission than the formal rules provide, see M Busuioc, "Accountability, Control and Independence: The Case of European Agencies" (2009) 15 European Law Journal 599, and, more recently, E Vos, "EU Agencies and Independence” in D Ritleng (ed.), Independence and Legitimacy in the Institutional System of the European Union (Oxford, Oxford University Press 2016) pp 206-28.
} 
hand, EFSA's internal rules and procedures for dealing with conflicts of interest have been strengthened progressively (with the latest round of amendments adopted in June 2017) and appear to be quite rigorous. Thus, in a recent review of the GFL, the Commission boasted that "EFSA has one of the most advanced and robust systems ensuring its independence". ${ }^{38}$ On the other hand, there were a number of examples of revolving doors, one of which made headlines across the world in 2012. It turned out that Diána Bánáti, chair of EFSA's Management Board, failed to disclose that she was a member of the board of International Life Sciences Institute (ILSI) Europe, an industry-sponsored association promoting the products EFSA is called upon to assess. She left ILSI after the link was exposed by a Green MEP, but the pressure in the European Parliament continued, so she resigned from EFSA to become ... a director of ILSI. ${ }^{39}$ This might be only the tip of the iceberg. In 2017, Corporate Europe Observatory, an NGO, identified that nearly half of the EFSA staff had some links to industry. ${ }^{40}$ While this is very worrisome, perhaps it should be taken with a pinch of salt. As Vos notes, "it is at the same time also evident that in practice scientists of good repute who could serve on staff committees of agencies will always be likely to be or have been involved in industry or national affairs". ${ }^{41}$ This is similar to the objections raised against IARC's experts, and although in this case no question of the exclusion of studies arises, once again we are facing integrity rules that determine who can sit on the panels and whose expertise must be excluded. Indeed, expertise is usually accompanied by interest, so it may be difficult to find a microbiologist with expertise on, say, GMOs who has not been involved in the development of one. Even if there is someone who conducted their research in academia only and with no external funding - something increasingly difficult by itself - the nature of their occupation is very likely to prejudice them to favour commercialisation of the product they have spent their lives working on. Similarly, it would be very difficult to find a biologist researching certain animal species who has no strong feelings for the conservation of these species. Thus, the specific disciplinary interest of the experts involved may bias them towards certain decisions even more decisively than any direct links with former employers. As Arcuri suggests, in the latter case, at least in principle experts may be able to act as if they were disinterested by allowing data to carry the day. ${ }^{42}$ On the other hand, the values that experts embrace, as a matter of disciplinary commitment, are likely to make a more lasting difference. For example, a microbiologist is likely to value innovation, an agronomist to value increasing crop yield and an environmental expert to value conservation. Depending on their respective representation on agencies' panels, the scientific conclusions of the latter may be different. Crucially, these disciplinary biases may very well be legitimate, as they embody ethical values that are recognised parts of their respective disciplines. Thus, it may be pointless to search for "an independent expert": the best that we can do

\footnotetext{
38 Executive summary of the REFIT Review, supra, note 17.

39 As a follow-up to this scandal, EFSA amended its rules to include two-year cooling-off periods.

40 COE, "Recruitment Errors", 17 June 2017 < https://corporateeurope.org/efsa/2017/06/recruitment-errors > (last accessed 11 November 2019).

41 Vos, supra, note 37.

42 See Arcuri, supra, note 8.
} 
is to make all such biases visible and to seek their diversification on the relevant boards and panels. Rather than insulating such panels, we should be seeking to reconstruct a "view from everywhere" within them. ${ }^{43}$ If the latter were the case, only covert interests would be problematic. Once again, the legal rules that determine who can sit on EFSA's Management Board and scientific panels affect the type of expertise that is deployed and therefore the content of the conclusions.

The differences between the set of studies that are taken into account by IARC and EFSA were already discussed, but now we need to reconsider them with regards to EFSA's aims and foundational regulations. ${ }^{44}$ Perhaps the most widely discussed difference was that EFSA possesses and must take into account proprietary studies conducted by the applicant. Paradoxically, while this is the biggest source of criticism of EFSA's decision, this is also its main defence: it might be that as a matter of law these studies ought to have greater weight than the academic literature, and in any event this, is how the Commission interprets the law. As the recent REFIT review of the $\mathrm{GFL}^{45}$ states:

As regards risk assessment in the context of authorisation dossiers, EFSA is bound by strict confidentiality rules and by the legal requirement to primarily base its assessment on industry studies, laid down in the GFL Regulation and in the multiple authorisation procedures in specific EU food legislation. These elements lead civil society to perceive a certain lack of transparency and independence, having a negative impact on the acceptability of EFSA's scientific work by the general public. There is therefore a need to address these issues in order to protect the reputation of EFSA's work. ${ }^{46}$

I have difficulties in finding where the GFL requires EFSA to base its assessment "primarily" on industry studies ("guideline studies"), but systematic interpretation of the Plant Protection Products Regulation suggests that this could be the case for pesticides. Article 8 of the latter provides quite comprehensive requirements for the content of the application dossiers and is clearly focused on the data that are to be gathered by the applicant. Only its very last paragraph says that "scientific peerreviewed open literature ... published within the last 10 years ... shall be added by the applicant to the dossier" ${ }^{47}$ While this may be understood to give certain priority to the industry studies to provide the minimum baseline data, it is far from clear that these studies should be given preference when other data are available. On the

43 For the phrase "view from everywhere", credit must be given to S Jasanoff, Science and Public Reason (London, Earthscan 2012) p 74; S Jasanoff, Designs on Nature: Science and Democracy in Europe and the United States (Princeton, NJ, Princeton University Press 2005) p 267, although she uses it with a somewhat different meaning.

44 For a more detailed comparison of the sets of studies, see Bozzini, supra, note 32. As she notes, where studies were available to both IARC and EFSA, the assessments of their merits and limits by each agency largely coincide; however, the two agencies followed different rules for weighting the reliability, relevance and consistency of these studies.

45 Regulation 178/2002 laying down the general principles and requirements of food law, establishing the European Food Safety Authority and laying down procedures in matters of food safety.

46 REFIT evaluation, supra, note 17 , emphasis in the original.

47 Although the heavy reliance on industry studies was one of the main criticisms of the current authorisations, and one of the three key demands of the European Citizens' Initiative "Ban Glyphosate" was to see this remedied, the amendments adopted in 2019 (supra, note 20) did not change this provision. 
contrary, in Paraquat, ${ }^{48}$ the General Court annulled the authorisation of a herbicide partly because the Commission failed to take into account several third-party studies. Notwithstanding these disagreements, if this is how priorities are understood by the Commission, there is little reason to expect that EFSA's panels are doing something different. As we shall see below, in the case of glyphosate, five industry studies were "key" and "pivotal" for EFSA's conclusion. ${ }^{49}$ Thus, it turns out that one particular interpretation of a single article in the relevant law predetermines which scientific study will carry the day. Notice that if the Commission or the Court were to change their views, the weighting of the studies could be different, and the conclusions of the "Science" as represented by EFSA could be entirely different.

\section{ENTANGLEMENT}

The detailed scrutiny of the way IARC and EFSA arrived at their conclusions provided in the preceding two sections already suggested that the entanglement between "law" and "science" goes very deep. This section will zoom in on this entanglement. First, it was seen that the very rules that serve to establish the integrity of the expert agencies and to ensure the highest quality of their expertise are not neutral to the substance of the scientific conclusions. Law provides criteria for the inclusion and exclusion of studies, and thus precisely delineates the epistemic basis for the scientific conclusions. Furthermore, there are regulations precisely delimiting the competences of the agencies (ie what issues they may or may not consider) that reflect the operational principles of the broader system each agency is embedded into. There are also the rules defining who can and who cannot sit on the respective panels, letting in certain types of expertise (eg how many microbiologists) and certain types of interests while excluding others (eg do representatives of civil society or the regulated industry get invited for consultations?). There are the guidelines to structure experts' discretion that prevent them from choosing or weighing conflicting evidence arbitrarily. There are the requirements for the form and content of the guideline studies provided by the applicant ${ }^{50}$ and for the final decision issued by the agency. Thus, contrary to the common understanding that expert advisors speak for some universal "Science", the legal rules to a great extent determine the scientific conclusions. While the scientists and the experts may have little direct interest in or understanding of law and politics, they are fully embedded in the respective legal environment and every step in their work is controlled by the law. ${ }^{51}$

That "scientific" is entangled with the "legal" and "political" has been robustly demonstrated by decades of research in STS. Yet outside of STS circles, this is

\footnotetext{
48 Case T-229/04 Sweden v. Commission (2007).

49 Words of José Tarazona, the Head of EFSA's Pesticides Unit, quoted by Corporate Europe Observatory, available at $<$ https://corporateeurope.org/efsa/2016/02/key-evidence-withheld-trade-secret-eus-controversial-risk-assessmentglyphosate $>$ (last accessed 8 November 2019).

50 See Commission Regulation (EU) No 283/2013 of 1 March 2013 setting out the data requirements for active substances.

51 In a rare explicit recognition of this, one of the members of the EFSA Management Board, Andres Szekacs, stated that "[EFSA] cannot consider everything for legal reasons", EFSA, 67th Management Board Meeting, 3 December 2015 $<$ www.efsa.europa.eu/en/events/event/151203\#playaudio> (last accessed 25 April 2018). I am grateful to Alessandra Arcuri for this reference.
} 


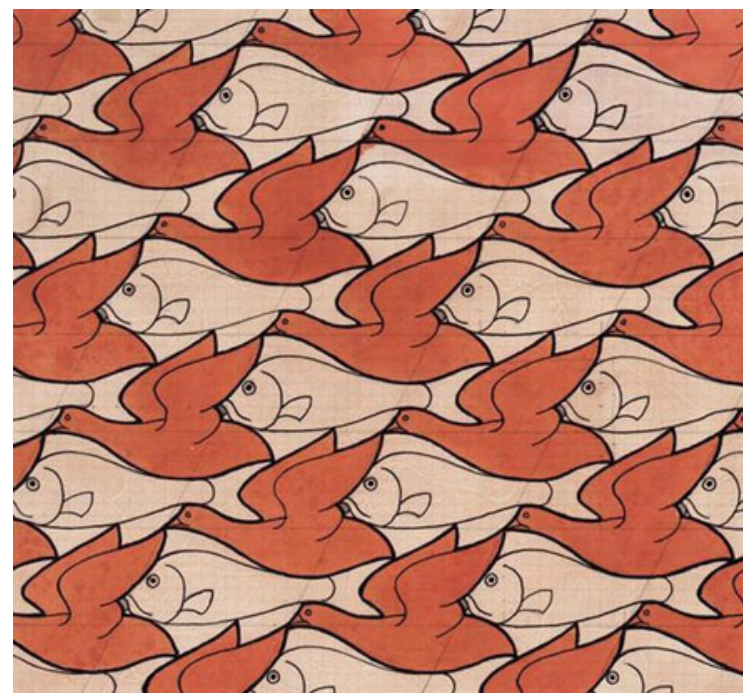

Figure 1. @ M.C. Escher, Bird Fish (1938).

usually understood merely to mean that the line between science and law must be either "reinforced" and/or drawn on a different place or at a different level. The glyphosate case stands out because two purely "scientific" agencies have reached opposite conclusions and, by focusing on the legal reasons for reaching these scientific conclusions, the present article hopes to have made clear that law and science are intertwined at every level, "all the way down". While we can distinguish law and science with a significant intellectual and oftentimes legal effort, they remain entangled pretty much like the fish and the birds in an Escher drawing (Figure 1). While in Figure 1 we can identify both the birds and the fish and tell one from the other, if we try to remove the fish, the birds also disappear (and vice versa). Similarly, if we want to remove the legal from the scientific, the latter would collapse into the opposite of science. ${ }^{52}$ Certainly, if we want to remove the science, the law would also lose its subject matter and vanish into thin air.

\section{LEVERAGE AND PROXY WARS}

As was mentioned above, initially carcinogenicity was not the main concern for the glyphosate protestors - it used to be just one concern amongst many. Furthermore, before 2015, these protestors insisted only on regular monitoring of its levels in food and the environment, for the adoption of glyphosate reduction programmes and for only certain uses (eg for desiccation) to be prohibited. What made carcinogenicity

\footnotetext{
52 This obviously applies to "regulatory science", which is the subject of this article, but "pure" science is not much different in the sense that it also relies on elaborate protocols and standards for quality, robustness and rigour. One may argue that, unlike law, these are internal and belong to the scientific field itself, but the division between internal and external would be no less problematic than the division between science and law.
} 
central and overwhelming in the worldwide public debate was not the evidence that was available at the time, but an obscure provision in the relevant EU legislation.

The Plant Protection Products Regulation seems to suggest that if a pesticide is formally classified as carcinogenic, then it cannot be authorised. While its Article 4 stipulates that EFSA must consider any "immediate or delayed harmful effects", and this seems to provide for some discretion, according to Annex II, 3.6.3, substances shall be approved only if, on the basis of the appropriate assessment, they are not classified as a category $1 \mathrm{~A}$ or $1 \mathrm{~B}$ carcinogen (exceptions apply). ${ }^{53}$

Thus, if glyphosate protestors could prove that glyphosate is carcinogenic, they could both scale up their demands and have a clear pathway to win on them. Annex II, perhaps unwittingly for its drafter, provided the protestors with leverage. Although this was but one issue within the big picture, some evidence for it could push the lever and bring about a planetary change.

Indeed, Annex II, 3.6.3 made it impossible for the producers to live with the claim that glyphosate is probably carcinogenic. ${ }^{54}$ They had to do all that they could to undermine IARC's claim (and did not have to bother very much with addressing any of the other concerns; nor had they to extoll any of its benefits). On the other hand, the environmentalists could seize the opportunity IARC had unexpectedly provided to contest the reauthorisation of glyphosate on this ground alone. And, of course, this particular ground would be perfectly sufficient for the regulators to act or not to act. Thus, all sides in the controversy had to make carcinogenicity a proxy for everything else that was at stake. This was acknowledged by EFSA's head, Bernhard Url, who complained in an opinion piece in Nature that scientific assessment suffers when "questions about a society's values are thrust onto scientific agencies rather than elected officials". ${ }^{55}$ He further argued that "when campaigners allege that EFSA did not follow due scientific process when assessing glyphosate ... they are really railing against bigger issues: the role of modern agricultural practices and multinational biotech firms in our food supply". I suspect that this is true, but I part company with Dr Url where he insists that elected officials and regulatory agencies have separate jobs that can and should be insulated from each other. ${ }^{56}$ To Dr Url's possible dismay, the legal and the scientific are entangled "all the way down", and any

\footnotetext{
53 While EFSA normally conducts risk assessments, the conclusions on carcinogenicity (as well as reproductive toxicity, neurotoxicity and endocrine effect) are hazard-based, and they appear to have lexical priority over the risk assessment conclusions. See A Székács and B Darvas, "Re-Registration Challenges of Glyphosate in the European Union" (2018) 6 Frontiers in Environmental Science 1, 22. Note also that although it is normally for the European Chemicals Agency (ECHA) to classify carcinogens, in this case EFSA was initially mandated to assess carcinogenicity, and ECHA's subsequent assessment appears to have been somewhat facultative.

54 This might have been so even without the said provision, as the "uncertainty paradox" suggests that risk producers, risk protestors and regulators become intolerant to any risk; see MBA van Asselt and E Vos, "EU Risk Regulation and the Uncertainty Challenge" in S Roeser, R Hillerbrand, P Sandin and M Peterson (eds), Handbook of Risk Theory: Epistemology, Decision Theory, Ethics, and Social Implications of Risk (Berlin, Springer 2012) pp 1119-36, 1128. Yet it is plausible to expect that the degree of their intolerance is not unrelated to the rigidity of the assessment regime.

55 B Url, "Don't attack science agencies for political gain" (2018) 553 Nature 381.

56 Indeed, the relevant legislation does separate risk assessment from risk management and "the bigger issues" (ie the non-scientific factors are to be considered only in the latter). However, it is uncertain whether this ever happens; see, eg, M Kritikos, "Traditional Risk Analysis and Releases of GMOs into the European Union: Space for Non-Scientific Factors?" (2009) 34 European Law Review 405. Moreover, as Fisher notes, any opening of the scientific models awakens resentment and creates opportunities for the contestation of their legitimacy; see Fisher, supra, note 12, p 303.
} 
attempt to insulate "science" further would inevitably take the form of law, thus increasing rather than curbing the entanglement.

There are two problems with the leverage effect. The first is the elevation of one consideration - important as it is - to the status of a trump card at the expense of all other legitimate considerations. The second is the arbitrariness. Such leverages may make favours to one party or another at random, or they may systematically favour one of the parties: either way is normatively problematic. ${ }^{57}$ While every rule may, in certain circumstances, provide leverage to someone and therefore this effect cannot be avoided ex ante, we should do a better job in recognising this effect and reflect on whether it works for our set normative goals or against them.

With the proxy wars, the first problem is that transparency is lost. We, the public, can see only the arguments of each side on the proxy issue, while most of the other relevant factors remain unheard of and often unmentioned. The other problem is substantive: the grounds for the ultimate decision are severely distorted. Indeed, the proxy issue may be less significant than many others that would warrant different outcomes if they had only seen the light of day. ${ }^{58}$ Furthermore, the issues cannot cumulate: whoever wins the proxy war wins it all. ${ }^{59}$

\section{CHOICE}

One may think that the legal regimentation of scientific assessments at every level reduces or removes the discretion from the system. This impression may well be reinforced by the way rules may be leveraged to force unexpected and momentous outcomes. Yet the careful reader should have noticed that at many points judgment and choice remain in the system. Choice is present at two levels. First, there is always space for the individual experts to interpret results, to trust one study more than another, etc. Second, when their choice is constrained by rules (or institutional context) - such as the preference for published or industry studies - in such cases the choice has already been made at the design level. At both levels the agents may genuinely believe that they are "objective"; they may well be unaware even that there is any other way to do their thing. Both the judgments they make and the rules they follow, by definition, prefer one type of expertise to another, one threshold to another, one scale of measurement to another, and as we have seen above, these are

\footnotetext{
57 For example, it has been shown that the system for GMO evaluation systematically favours the industry side; see $\mathrm{P}$ Anderson, "What Rights Are Eclipsed When Risk Is Defined by Corporatism? Governance and GM Food" (2004) 21 Theory, Culture \& Society 155. More recently, see L Levidow, "Substituting a Fictional 'Science' for Public Accountability: Legitimacy Problems of the EU's Regulatory Framework for GM Products" in LE San-Epifanio (ed.), Towards a New Regulatory Framework for GM Crops in the European Union (Wageningen, Wageningen Academic Publishers 2017) pp 155-66. Note, however, that sometimes we may have good reasons to design the system to favour one party. An example of this is the precautionary principle, which is meant to give leverage to those who speak for the environment.

58 Cf Lee, supra, note 17, p 277: "The false accountability provided by risk might lead to premature closure of the political debate, encouraging a sometimes sterile debate on competing science".

59 In the author's personal experience, risk protestors have acquiesced to this travesty of science-based risk analysis to a great extent. They have internalised the view that only hard science matters, so much so that a prominent environmental organisation rejected a paid report on GMO regulation where I made a similar argument for fear of appearing "antiscience". The report was later published by another organisation; see V Paskalev, "An Assessment of Current Regulation of GMOs in the EU and Proposals for Amending It", The Greenhouse Report Series (2016) <www. greenhousethinktank.org/uploads/4/8/3/2/48324387/gm_inner.pdf> (last accessed 4 April 2020).
} 
not neutral to the outcome. The glyphosate saga provides three neat examples that illustrate the irredeemable choices at each level.

\section{The importance of dead mice}

The first of the five industry studies that were pivotal for the EFSA decision ${ }^{60}$ was conducted as early as 1983 in preparation for the initial authorisation application in the USA. ${ }^{61}$ It provides a particularly vivid illustration of discretion at the individual level. The competent authority in America - EPA - initially understood the study as showing some carcinogenic effect at higher exposure levels, so it classified glyphosate as possibly carcinogenic to humans. Three years later, EPA - after some exchanges with Monsanto ${ }^{62}$ - agreed that the findings were not unequivocal, so they consented to classifying glyphosate as safe, but insisted that the study be repeated. ${ }^{63}$ Monsanto balked, and by 1991, EPA dropped its demand, thus clearing glyphosate completely. As IARC obtained the study through EPA, it could take it into account and interpret it as showing carcinogenic effect. ${ }^{64}$ The same study was interpreted yet again by EFSA, but favourably. The point to take home from this example, however, is not that the agencies and the experts working in them were choosing their interpretations according to their liking. ${ }^{65}$ It only shows that the scientific conclusions were not as hard and fast as lawyers and laymen alike tend to believe. Notwithstanding their dependence on data - mice tissue in this case - they are also a matter of judgment, judgment informed by the full array of evidence available to the experts who make them, as well as their disciplinary commitments, ${ }^{66}$ and, of course, by their individual professional experience. I shall return to this below.

\section{Vice and virtue of guideline studies}

As we saw, EFSA is required to prefer industry studies to academic literature, a design choice that is particularly controversial. ${ }^{67}$ Three other pivotal studies that are more recent

\footnotetext{
60 See the text accompanying note 49.

61 A Knezevich and G Hogan, “A Chronic Feeding Study of Glyphosate (Roundup Technical) in Mice: Project No. 77-2061: BDN-77420. Final rept. (Unpublished study received Aug 17, 1983 under 524-308; prepared by Bio/dynamics, Inc., submitted by Monsanto Co., Washington, DC; CDL:251007-A; 251008; 251009; 251010; 251011; 251012;251013;251014; (MRID 00130406)" (1983).

62 Letters available at the US Right to Know website, see links from "Of Mice, Monsanto and a Mysterious Tumor" $<$ https://usrtk.org/pesticides/of-mice-monsanto-and-a-mysterious-tumor> (last accessed 11 November 2019).

63 If one is wondering, the reason why two diametrically opposing interpretations of the same study are possible is that the mice were given glyphosate at doses of 150,1500 or $4500 \mathrm{mg} / \mathrm{kg}$ body weight per day, and negative effects were observed in males at the highest dose only. Thus, one can validly conclude both that "glyphosate is carcinogenic" and that "lower doses are safe". But then the question of safety hinges on what the actual exposures are, and these vary widely and necessitate entirely different types of expertise in order to be determined.

64 IARC, Monograph 112 (2017), p 394.

65 Nor, in the view of the present author, does it show the biases that the agencies are respectively accused of.

66 See the discussion on disciplinary interests in Section IV.

67 That is why the European Citizens' Initiative "Ban Glyphosate" demanded that "the scientific evaluation of pesticides for EU regulatory approval is based only on published studies, which are commissioned by competent public authorities instead of the pesticide industry". The reforms that were eventually adopted in 2019 (note 20) stopped quite short of this, providing only for publication of the industry studies and public register for all industry research so that unfavourable findings cannot be withheld.
} 
remain unpublished, ${ }^{68}$ and they were made available to EFSA (and EPA), but could not be taken into consideration by IARC. As they were not subject to any peer review, their only quality imprimatur is the compliance with the Organisation for Economic Co-operation and Development (OECD) Guideline 451 and Good Laboratory Practice (GLP) guidelines. ${ }^{69}$ While it is far from certain whether peer review per se is a guarantee of quality and reliability, ${ }^{70}$ the publication and availability of the raw data are key factors in ensuring that misinterpretation, errors and fraud will be discovered. On the other hand, the compliance with certain protocols, even if they are very strict which itself is a point of contestation - cannot substitute the critical eye of the rival or opponent. Thus, EFSA's conclusion came under fire immediately. Dr Christopher Portier and some 100 colleagues addressed an open letter to the European Commission to disregard EFSA's assessment because of, inter alia, its reliance on these studies. ${ }^{71}$ In a companion academic article, they argued that "[c]ompliance with guidelines and Good Laboratory Practice does not guarantee validity and relevance of the study design, statistical rigour and attention to sources of bias". ${ }^{72}$ There are several design choices that become obvious here. The first is the choice of the EU legislator (or possibly of the Commission, as discussed above) to rely predominantly on industry studies. Then there is a set of choices made by the drafter of the guidelines - in OECD and possibly in rival organisations. Finally, there are a number of individual or institutional choices made by research organisations all over the world for validating their research (eg compliance with GLP or peer-reviewed publication), thus making them eligible for some uses and ineligible for others.

\section{Animal testing versus epidemiology}

Further to these choices, which are made more or less explicitly, there are pathways selected inadvertently by some other institutional circumstances. This is illustrated by the different weight of the experimental and the epidemiological research. For assessment of toxicity there are two major types of studies. The first is animal studies, where a group of lab animals are exposed to the substance under investigation and their well-being is compared to a control group of animals in the same environment with the only difference being that they are not subject to the treatment. This is accepted to prove causal relationships. The trouble is that not all effects that are observed in animals will affect humans. As it would be unethical to make similar experiments with humans, adverse effects on humans are observed through the second major type of toxicity

\footnotetext{
68 "Carcinogenicity Study with Glyphosate Technical in Swiss Albino Mice" (2001), owned by the Israeli company ADAMA Agan Ltd (unpublished); "Glyphosate Technical: Dietary Carcinogenicity Study in the Mouse" (2009), study owned by the Australian company Nufarm (unpublished); "HR-001: 18-Month Oral Oncogenicity Study in Mice" (1997), owned by the Japanese company Arysta LifeSciences Corporation (unpublished).

69 Note the other avenues for the regimentation of science here.

70 A spoof paper with obvious mistakes submitted to some 200 peer-reviewed journals was accepted by nearly half of them; see J Bohannon, “Who's Afraid of Peer Review?” (2013) 342 Science Magazine 60.

71 The open letter by Portier and colleagues to the European Commission is available at $<$ https://www.efsa.europa. eu/sites/default/files/Prof_Portier_letter.pdf > (last accessed 11 November 2019).

72 CJ Portier et al, "Differences in the carcinogenic evaluation of glyphosate between the International Agency for Research on Cancer (IARC) and the European Food Safety Authority (EFSA)" (2016) 70 Journal of Epidemiology and Community Health 741, 743 (with reference to JP Myers et al, "Why public health agencies cannot depend on good laboratory practices as a criterion for selecting data" (2009) 117(3) Environmental Health Perspectives 309).
} 
study: epidemiological studies, where the conditions of a large group of people who are exposed to the substance anyway is compared with a similar group of people who are not so exposed. The problem with this is that the similarity of the two groups is never sufficient to prove causality - even if we control for factors such as age, smoking, etc., the differences between the two groups may still be attributed to factors other than the exposure to the substance in question.

While IARC can rely on both experimental and epidemiological studies, for EFSA it is more difficult to rely on the latter. While animal studies can be conducted with pure glyphosate, epidemiological studies are mostly of compounds, as glyphosate is normally used in compounds. The available compounds vary greatly, and many of the additives can have adverse effects too. The broader subject of IARC's assessment allows for the accumulation of the studies of different mixtures. In contrast, for EFSA the other chemicals in the mixtures are confounding factors to control for and their results will be less conclusive, ${ }^{73}$ so it only "recognised" that the issue of the toxicity of compounds should be studied further and that "some" studies of mixtures presented positive results. ${ }^{74}$ Thus, the "technical" differences between the subject of assessment of each agency determines the respective selection of the studies and influences the weight of the different types of evidence. The implicit design choice made with the respective terms of reference should be apparent. On the other hand, the (im)possibility for accumulation and the difficulties with the confounding factors provide space for individual judgments. As one of the IARC experts noticed, they had to decide whether it is only some of the mixtures that are problematic or whether it is glyphosate itself to blame. On the preponderance of the evidence, they consciously decided that the latter was the case. ${ }^{75}$

By digging into so much technical detail, this section provided some evidence to support the main argument of this article that discretion and choice are irredeemable even in the most strictly regimented science-based risk analysis. This is a radical challenge to the common understandings both in law and in science. Each of these enterprises is based on the assumption that they are objective and that, if their practitioners are doing their jobs properly, there is little choice left. While this may appear to be the case, when we look beneath the surface we can find that even the most "technical" and controlled issues leave some space for judgment. This is not to say, however, that conclusions in science (or in law $^{76}$ ) are arbitrary either. I hope I have shown that the picture is far more nuanced and that these judgments can be based on legitimate methodological reasons (eg preference for published/unpublished reports, peer-reviewed/proprietary research, epidemiological studies/laboratory experiments, etc.). Thus, just like Schrödinger's cat, which can be dead and alive at the same time, expert conclusions can be both predetermined (by law or by science's own protocols) and discretionary. Even when

\footnotetext{
73 Note, however, that one of the key studies "exculpating" glyphosate - the AHS, discussed above - is epidemiological.

74 EFSA, "Conclusion on the peer review of the pesticide risk assessment of the active substance glyphosate" (2015) 13(11) EFSA Journal 4302.

75 Anonymous expert interviewed by A Arcuri; see Arcuri, supra, note 22, pp 243-44.

76 As Tribe and Dorf put it in the context of the question for objectivity of law, "to recognise the limits of human objectivity does not require that we abandon the effort to approximate those limits"; LH Tribe and MC Dorf, "Levels of Generality in the Definition of Rights" (1990) 57 The University of Chicago Law Review 1057.
} 
it appears to the individual experts that they have no choice whatsoever and that every step they make is predetermined by facts or rules, at the system level we can always identify how small tweaks here and there could lead to very different results.

The practical implication of this bold theoretical claim is that we should be well aware of these dynamics and design our systems for risk analysis accordingly. This is not the case now: the science-based paradigm casts a veil of objectivity such that the space for choice is largely unnoticed and most reform efforts are bent on "strengthening" science and separating it even more rigidly from law or from politics. ${ }^{77}$ While the notion of "science-based" regulation is intuitively appealing, if the analysis above is correct, all such efforts are bound to fail because the "scientific" and the "legal" are no more separable than the yolks and the whites in the omelette. It bears repeating that the reason for this is not the (deficient) integrity of the experts - although sometimes this may be the case - but that even the most technical conclusions may be dependent on the context (ie on the "political"). I hasten to add that the entanglement with the legal, or, indeed, with the political, does not make the "scientific" arbitrary. Nothing in this article should be understood to mean that "Science" or scientific assessments are always arbitrary, nor does it attempt to revive the worn-out debate on relativism. My only claim is that science, or at least science that is relevant for regulation, cannot be "pure". There will always be some rules that structure decision-making in scientific bodies and the judgments of individual experts, and even what appears to be a scientific question will always be determined by rules (ie by law in one of its many modes of existence) just as much as by data.

\section{Conclusion}

In this article, I showed that science and law are entangled, like the proverbial turtles "all the way down". Indeed, their relationship is best illustrated by an Escher painting (Figure 1), where the fishes and the birds shape and even constitute each other. Furthermore, I argued that decision-making is at the same time a heavily regimented process and a discretionary one. Even though regimentation and discretion appear to be antithetical, this is possible: the choice is constrained, and the rules can remove it from some places, but only to shift it to other places or to another level, often unwittingly. The struggle for "depoliticisation" and "science-based" regulation tends to shift discretion towards less accountable bodies upstream, but it does so by making design choices at the political level that are by no means neutral to the content of the scientific assessment. Thus, in my view, the right question to study is not how to disentangle law and science or where to draw the border, but how any given border shifts the locus of choice (discretion), what choices have been made unwittingly when the border was drawn and what tiny but possibly decisive choices are made with every individual scientific judgment. Finally, scholars and regulators alike should never let the focus on "objectivity", accountability and adherence to rules prevent us from seeing the bigger picture and divert our attention from the plethora of issues that any regulatory controversy places at stake.

77 The reform of the GFL (see note 20 above) is no exception, but this is beyond the scope of this article. 